\title{
A Numerical Study of the Summertime Flow around the Luzon Strait
}

\author{
Ching-Sheng Chern and Joe Wang \\ Institute of Oceanography, National Taiwan University, Taipei, Taiwan, Republic of China
}

(Received 6 March 1997; in revised form 3 September 1997; accepted 4 September 1997)

\begin{abstract}
Luzon Strait, a wide channel between Taiwan and Luzon islands, connects the northern South China Sea and the Philippine Sea. The Kuroshio, South China Sea gyre, monsoon and local topography influence circulation in the Luzon Strait area. In addition, the fact that the South China Sea is a fairly isolated basin accounts for why its water property differs markedly from the Kuroshio water east of Luzon. This work applies a numerical model to examine the influence of the difference in the vertical stratification between the South China Sea and Kuroshio waters on the loop current of Kuroshio in the Luzon Strait during summer. According to model results, the loop current's strength in the strait reduces as the strongly stratified South China Sea water is driven northward by the southwest winds. Numerical results also indicate that Kuroshio is separated by a nearly meridional ridge east of Luzon Strait. The two velocity core structures of Kuroshio can also be observed in eastern Taiwan. Moreover, the water flowing from the South China Sea contributes primarily to the near shore core of Kuroshio.
\end{abstract}

\author{
Keywords: \\ - South China Sea, \\ - Luzon Strait, \\ - Balintang Channel, \\ - Kuroshio, \\ - loop current, \\ - frontal geostrophic \\ equation.
}

\section{Introduction}

Luzon Strait (LS) is a wide channel between Taiwan and Luzon islands. Eastward of the LS, Kuroshio flows northward along the eastern coasts of Luzon and Taiwan. According to previous hydrographic surveys and satellite images of the sea surface temperature, the path of Kuroshio in the LS has two distinct patterns: (a) the jet flows directly north passing the strait (Nitani, 1972; Wang and Chern, 1996), and typically occurs in summer; and (b) a portion of Kuroshio water flows westward through the LS and forms a loop current, attributed to the onset of a northeasterly monsoon wind (Wang and Chern, 1987; Farris and Winbush, 1996). Shaw et al. (1996) also noted that the westward intrusion of Kuroshio across the LS may contribute to the winter gyre in the South China Sea (SCS).

In addition to wind effects mentioned above, a recent numerical model study by Li et al. (1996) indicated that the northward flowing western boundary current, similar to Kuroshio, always deforms at a gap of the western boundary and forms an anticyclone loop current as the gap becomes sufficiently wide. Therefore, we may regard the occurrence of the Kuroshio loop current in the LS and the accompanying westward intrusion of Kuroshio water north of Luzon as a normal flow pattern. Hence, the retreat of Kuroshio's westward intrusion and weakening of the loop current in the LS during the summer season may be ascribed to the northward movement of the SCS water driven by southwesterly winds. The following sections present a numerical model to test this notion.
Our model study also demonstrates that Kuroshio tends to separate into two branches as it encounters a meridional ridge to the east of LS. The branch, which passes the Balintang Channel, can interact with the SCS water in the LS.

\section{Hydrography}

The circulation of SCS relies heavily on the monsoon winds. During summer, Shaw and Chao (1994) demonstrated that the southwest winds drive the surface SCS waters northward and transport them to the region east of Taiwan. Wang and Chern (1996) gave a thorough description of the summer hydrography in the northern SCS based on joint surveys conducted by the R/V Ocean Research $1, \mathrm{R} / \mathrm{V}$ Ocean Research 3, R/V Xian-Yang-Hong 14 and R/V Yang-Ping 2, during the period August 28 to September 10, 1994. According to those results, the SCS waters occupied the northern SCS to the west of LS and subsequently formed a cyclonic circulation. The front between the SCS water and Kuroshio water, originating from the Balintang Channel, was in the meridional direction in the strait during the survey period. The results presented in the following are later compared with those of the numerical model.

Figure 1 depicts the bathymetry in the vicinity of the LS area and our model domain. The main features include the continental shelf along the southern China coast, Peng-hu Channel, Luzon Strait and the Balintang Channel. Eastward of LS, the isobath is nearly parallel to the longitude line and forms a submarine ridge system between Taiwan and the 


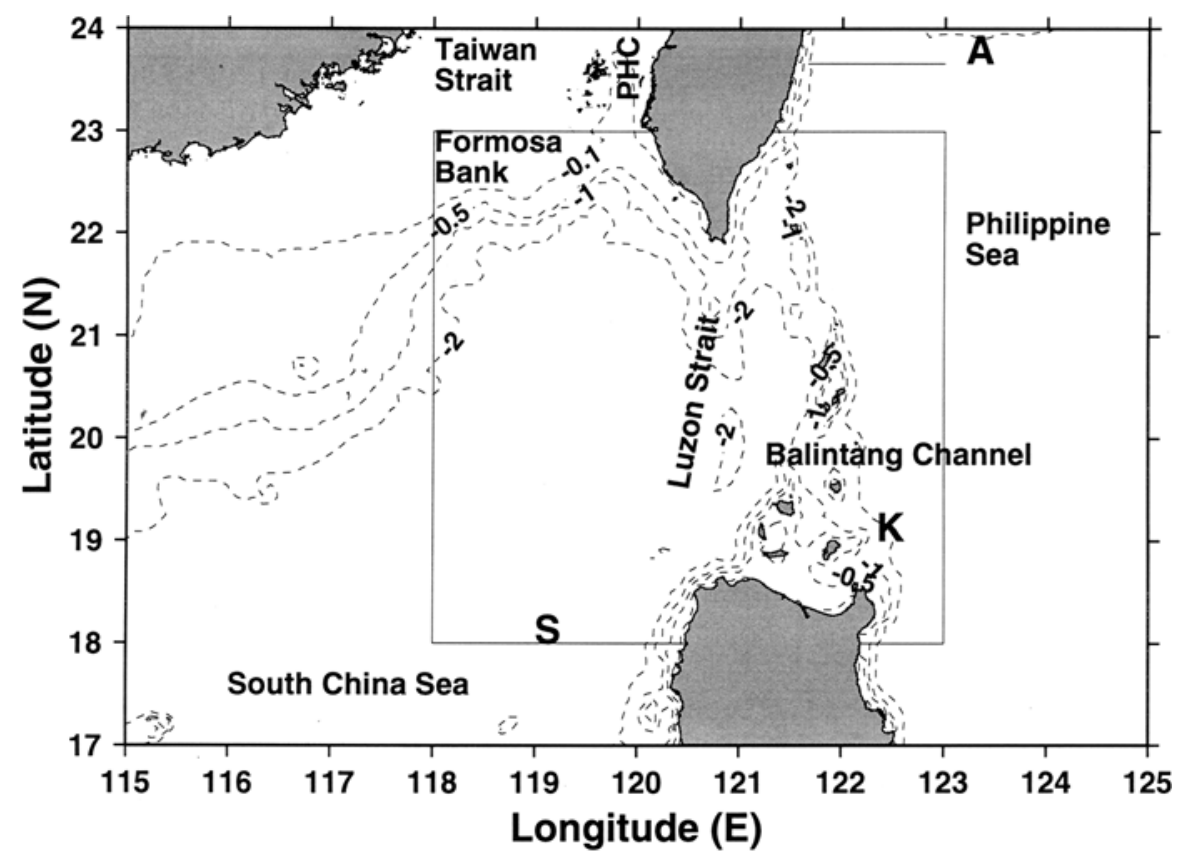

Fig. 1. The seas surrounding Luzon Strait area. The depth contours are in $\mathrm{km}$ and PHC denotes the Peng-hu Channel. A is the position of the transect line shown in Fig. 5 and $S, K$ are the positions of water samples whose temperature profiles and associated (T, S) curves are shown in Fig. 2. The rectangle inside the figure is our model region.

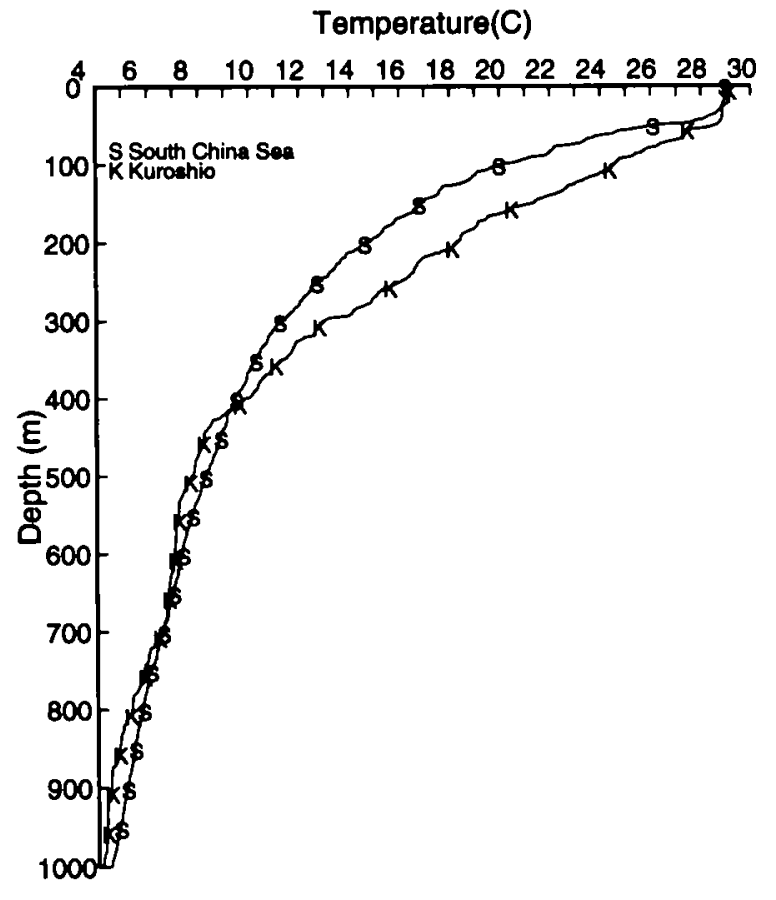

(a)

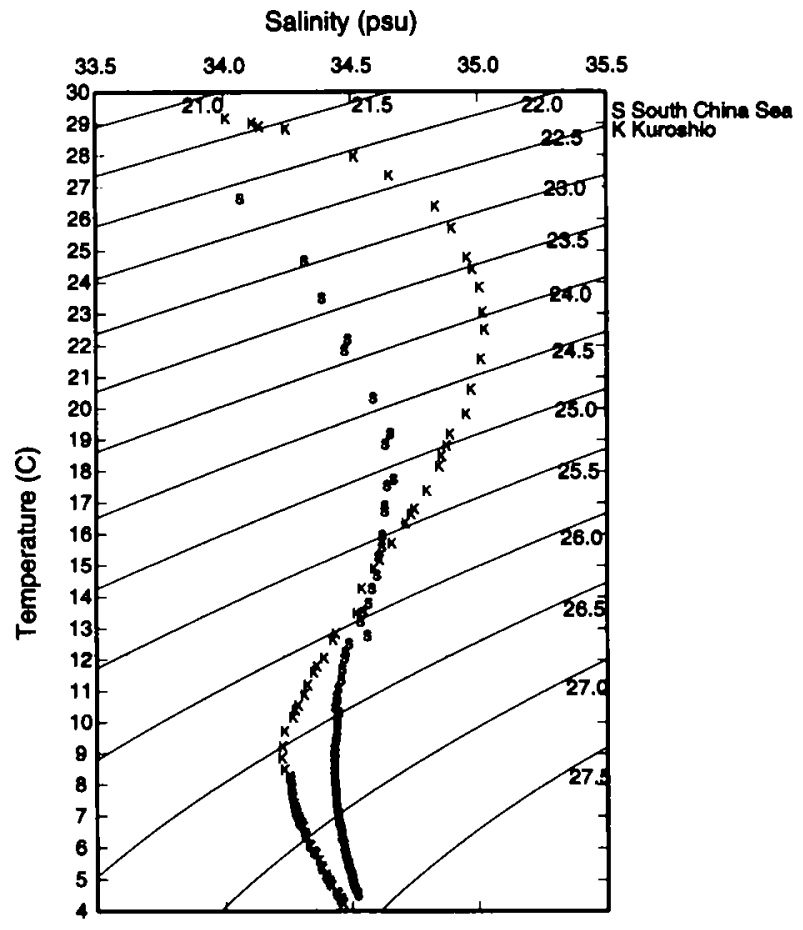

(b)

Fig. 2. Typical vertical temperature profiles (a) and (T, S) scatter diagram (b) of the SCS water, Sta. S, and Kuroshio water, Sta. K. 
1994 8/28-9/10 Temperature (C) at $125 \mathrm{~m}$

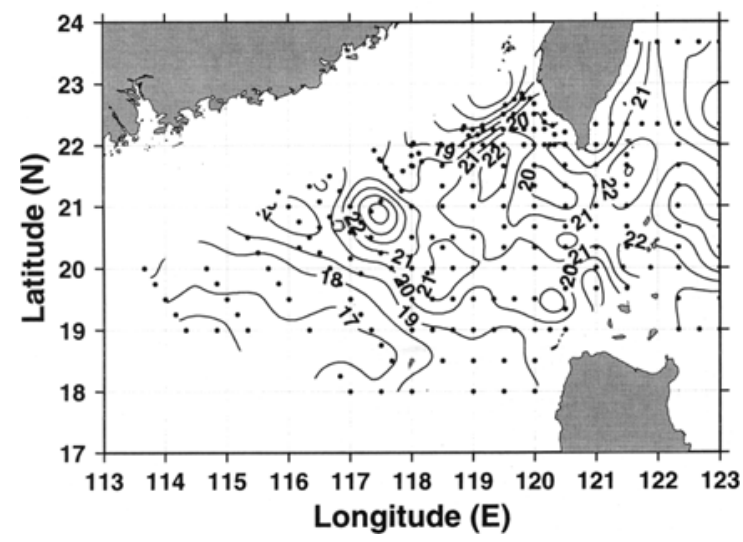

$19948 / 28-9 / 10$ Salinity (psu) at $125 \mathrm{~m}$

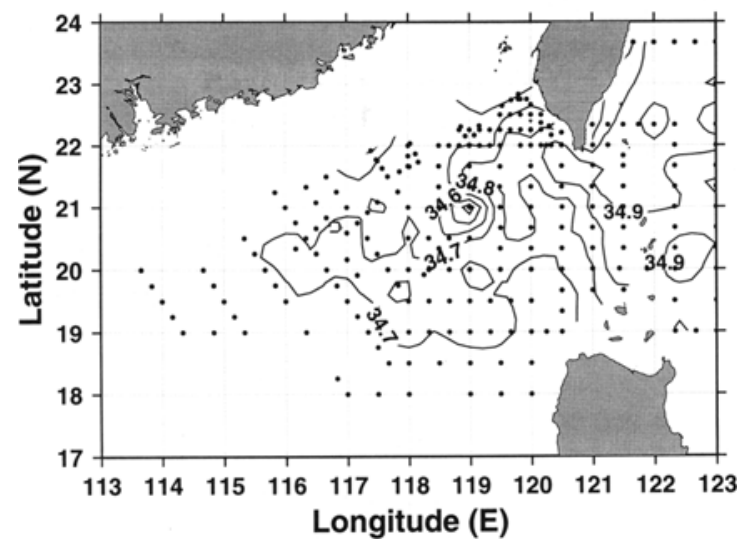

Fig. 3. Horizontal temperature and salinity distributions at $125 \mathrm{~m}$ of the survey during 1994/8/28-9/10.

Balintang Channel. This ridge system and Taiwan, Luzon constitute the western boundary of the Philippine Sea. Liu et al. (1995) reported some evidence of the influence of this ridge system on the local circulation near southern Taiwan.

SCS, a fairly closed basin, has markedly different water masses than the adjancent seas. Figure 2 displays the the vertical temperature profiles of the SCS water and the Kuroshio water (a) and the corresponding (T, S) scatter diagram (b). The positions of these water samples are shown in Fig. 1. Figure 2(b) reveals that the salinity of Kuroshio in the Philippine Sea has a maximum $>34.9$ psu and minimum at around $34.3 \mathrm{psu}$. The SCS water has a smaller salinity maximum value, $<34.7 \mathrm{psu}$, and a larger salinity minimum value, $>34.4$ psu. Figure 2(a) indicates that the SCS water is cooler than Kuroshio water in the Philippine Sea in the 50$400 \mathrm{~m}$ depth range. This finding is consistent with the numerical results of Chao et al. (1996), which demonstrated that the southwestern offshore of Taiwan is one of the primary deep upwelling regions responsible for deep water
1994 8/28-9/10 Temperature (C) at $325 \mathrm{~m}$

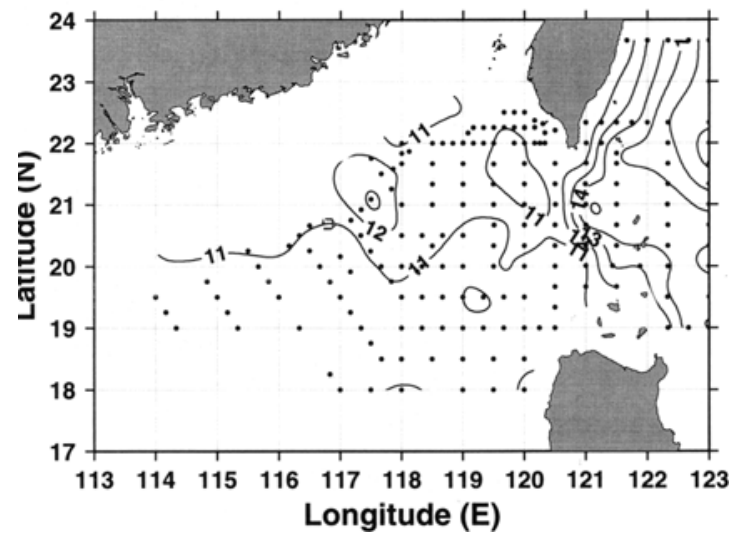

1994 8/28-9/10 Salinity (psu) at 325 m

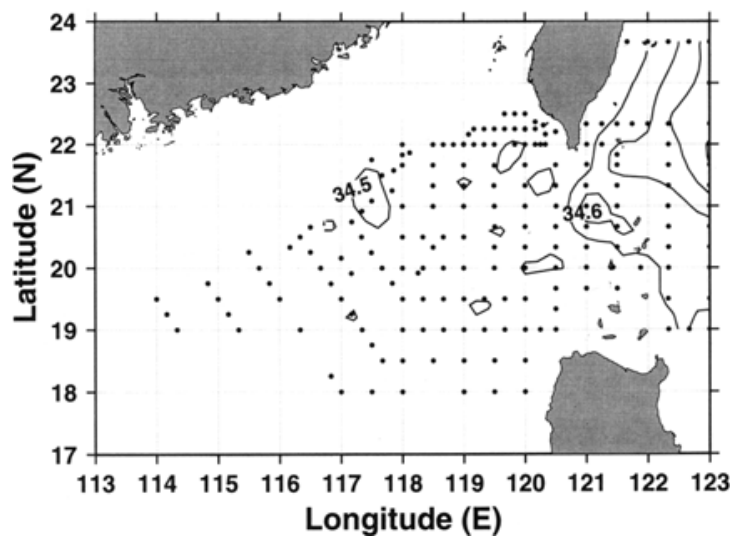

Fig. 4. Horizontal temperature and salinity distributions at $325 \mathrm{~m}$ of the survey during 1994/8/28-9/10.

renewal of the SCS. This difference between the SCS water and Kuroshio water has also been observed during other survey periods (Chern and Wang, 1995).

Figure 3 presents the temperature and salinity contour at a depth of $125 \mathrm{~m}$. The Kuroshio front in the LS is unclear at this depth. As this figure reveals, some cold and less saline SCS water, with temperature $<20^{\circ} \mathrm{C}$ and salinity $<34.7 \mathrm{psu}$, flows northward along the shelf margin north of Luzon and converges with Kuroshio water with salinity $\geq 34.9$ psu in the LS. Westward of LS, the cold and less saline water, temperature $<20^{\circ} \mathrm{C}$ and salinity $<34.7 \mathrm{psu}$, occurs primarily at south of $20^{\circ} \mathrm{N}$ and along the continental slope south of Formosa Bank. Figure 4 illustrates the temperature and salinity contour at a depth of $325 \mathrm{~m}$. At this depth, both the temperature and salinity front associated with Kuroshio are well defined in the LS and form a small clockwise loop structure at southern Taiwan. Westward of this front, the water has a uniform distribution of temperature (about 
(a)

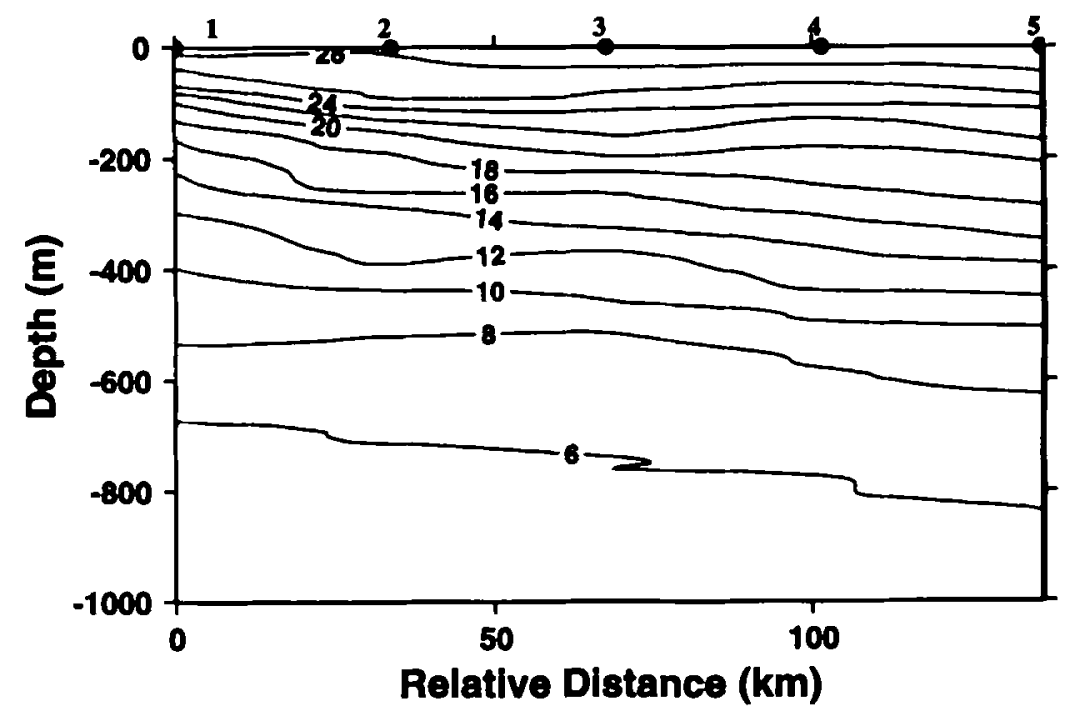

(b) Salinity at $23.66 \mathrm{~N}$

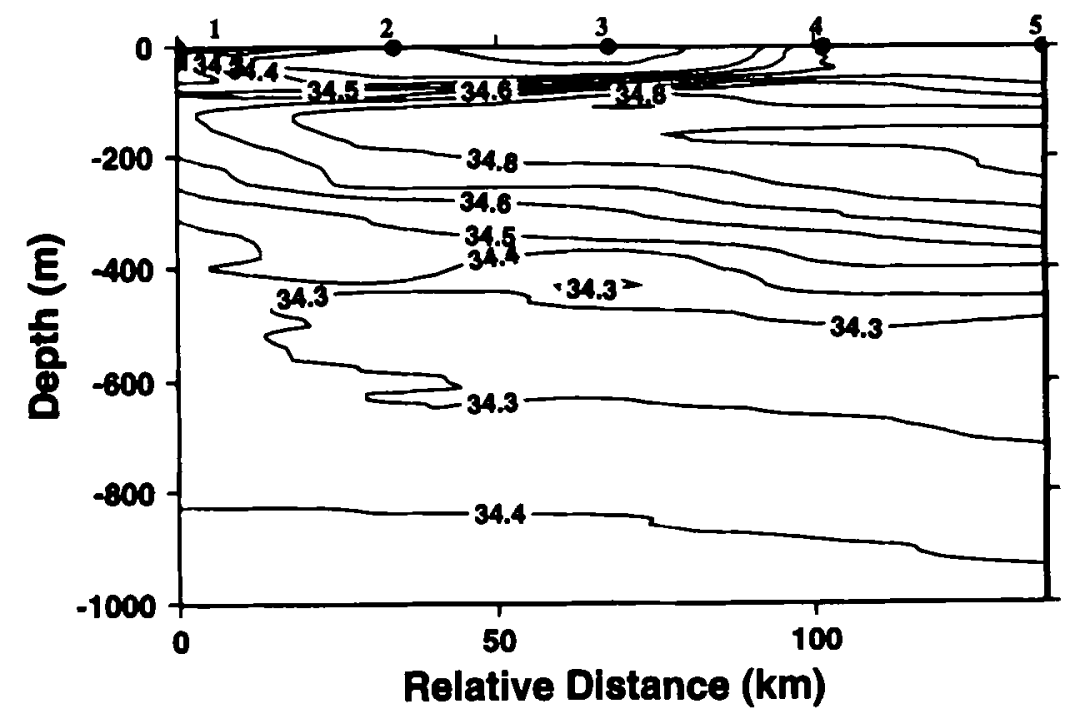

Fig. 5. Temperature (a), salinity (b) and geostrophic velocity (c) transects along line A in Fig. 1. The numbers on top of the frame are the station numbers of the CTD casts.

$11^{\circ} \mathrm{C}$ ), and salinity (about $34.5 \mathrm{psu}$ ).

From the temperature contour at $325 \mathrm{~m}$ we can infer that the temperature front is quite narrow in the LS and becomes wider at eastern Taiwan. This finding suggests that Kuroshio water east of Taiwan does not entirely originate from the LS. Figure 5 shows the temperature, salinity and geostrophic velocity transects at $23.66^{\circ} \mathrm{N}$, between $121^{\circ} 40^{\prime}$ $\mathrm{E}$ and $123^{\circ} \mathrm{E}$, line $\mathrm{A}$ in Fig. 1. The numbers on the top axis of Fig. 5 denote the stations of our CTD casts and the origin of the relative distance is at $\left(121^{\circ} 40^{\prime} \mathrm{E}, 23^{\circ} 40^{\prime} \mathrm{N}\right)$. In addition, the geostrophic velocity is calculated from the tem- perature and salinity data with an assumed reference level at $1000 \mathrm{~m}$. The velocity distribution, Fig. S(c), clearly reveals that two velocity cores are present. The near shore core, between Stn. 1 and Stn. 3, is roughly $50 \mathrm{~km}$ wide and $400 \mathrm{~m}$ deep with a surface velocity exceeding $100 \mathrm{~cm} / \mathrm{s}$. The other core, ranging between Stn. 3 and Stn. 5, extends to a deeper depth and has a weaker vertical shear. According to the salinity transect, Fig. 5(b), the offshore core has a salinity maximum $>34.9 \mathrm{psu}$, indicating its origin in the water of the Philippine Sea. The fact that the salinity maximum of the near shore core is $\leq 34.8 \mathrm{psu}$ implies that the constituents of 
(c)

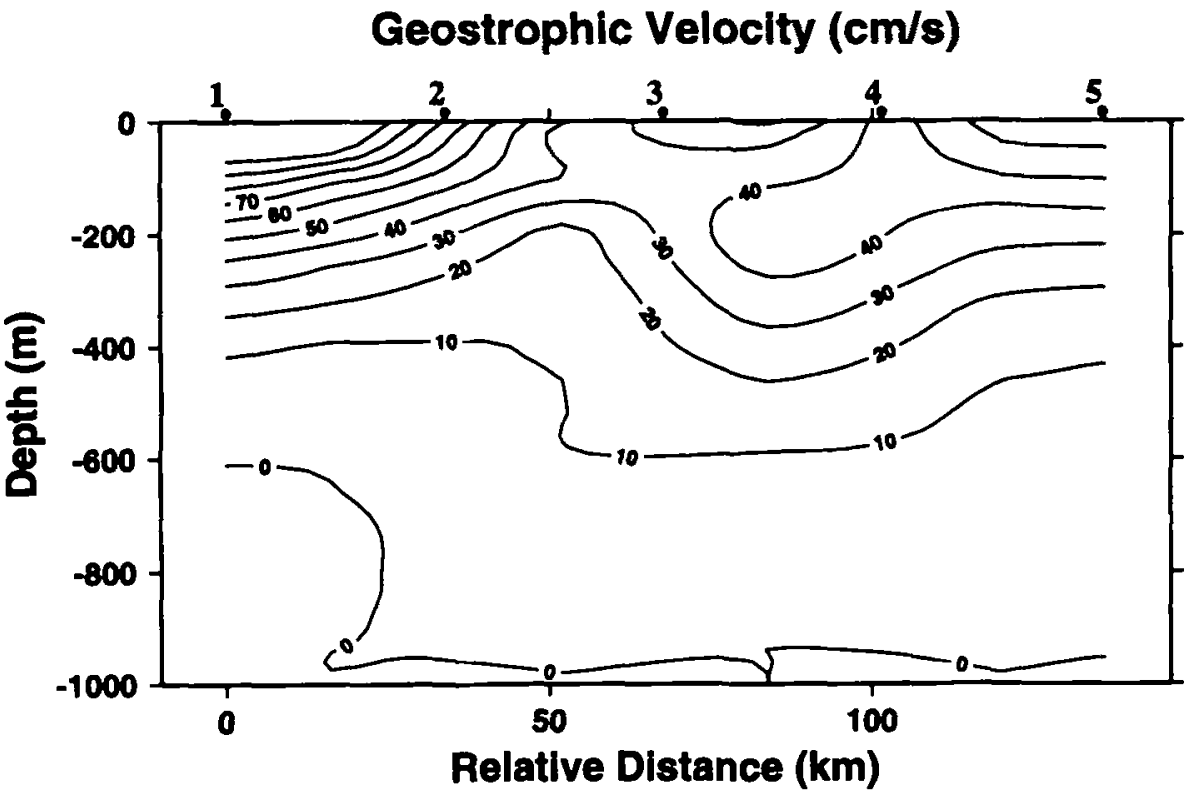

Fig. 5. (continued).

the near shore core are a mixture of water from the Balintang Channel and the northward flowing SCS water. The temperature transect, Fig. 5(a), also indicates that the offshore core has a weaker vertical stratification and the near shore core has a strong thermocline between $20^{\circ} \mathrm{C}$ and $24^{\circ} \mathrm{C}$. This finding suggests that the SCS water contributes to the near shore core of Kuroshio in eastern Taiwan.

\section{Numerical Model}

The ocean general circulation model described by Semtner $(1974,1986)$ is adopted here to investigate the flow in the LS area. Figure 6 depicts the model basin of our study area. The model domain is a rectangular channel of $53 \times 55$ grids in the horizontal plane. The mesh size is $10 \mathrm{~km}$ in both $x$ and $y$ directions. The fact that the difference between the SCS water and Kuroshio water is small at a depth of around $1000 \mathrm{~m}$ (Fig. 2) accounts for why this study only examines the flow above $1000 \mathrm{~m}$ in our model. Hence, we use vertical twelve levels, with $25 \mathrm{~m}$ in the top four levels, $50 \mathrm{~m}$ in the next three levels and $150 \mathrm{~m}$ in the lower five levels, yielding a maximum basin depth of $1000 \mathrm{~m}$. In our model basin, the main topographic features are the shallow Formosa bank at the northwest of the model domain, a triangular shelf north of Luzon island and a meridional ridge at east of LS.

A geostrophic jet is initialized to follow the eastern coast of Luzon and the meridional ridge east of LS. There are only limited data sets about the structure and the associated variations of the Kuroshio east of Luzon. Nitani (1972) indicated that the volume transport of Kuroshio east of Luzon is $36 \mathrm{~Sv}$ and $20 \mathrm{~Sv}$ for the summers in 1965 and 1966, respectively. Chu (1976) also noted that the Kuroshio trans- port at $24^{\circ} \mathrm{N}$ may vary from $19 \mathrm{~Sv}$ to $42 \mathrm{~Sv}$. The velocity distribution in Fig. 5(c) yields a volume transport of around $25.8 \mathrm{~Sv}$. Hence, we consider two different volume transports of Kuroshio to the east of Luzon in the following discussions. In Case I, the volume transport of Kuroshio east of Luzon is $20 \mathrm{~Sv}$ and the maximum surface velocity of the jet is around $60 \mathrm{~cm} / \mathrm{s}$. Figure 7 presents the cross section of its temperature and velocity distributions at the southern open boundary east of Luzon. Figure 7 indicates that the jet is trapped at east coast of Luzon, at grid 41, and has a width around $100 \mathrm{~km}$. In Case II, the volume transport of Kuroshio east of Luzon increases to $24.3 \mathrm{~Sv}$. The temperature distribution across the jet in Case II is similar to the one shown in Fig. 7, except that the horizontal length scale of the jet is reduced to $80 \mathrm{~km}$. Therefore, the horizontal temperature gradient and the geostrophic velocity relative to $1000 \mathrm{~m}$ are enhanced. The maximum surface velocity of the jet is about $81 \mathrm{~cm} / \mathrm{s}$ in Case II. The structure of Kuroshio shown in Fig. 7 resembles the one used in our previous study of Kuroshio's intrusion across the continental shelf northeast of Taiwan (Chern and Wang, 1994). The temperature section at the southern open boundary east of Luzon is held constant during the integration of the model. The initial salinity field is calculated from the temperature field based on the $\mathrm{T}-\mathrm{S}$ curve of Kuroshio water shown in Fig. 2(b). For the region west of the jet, their initial $(T, S)$ values are set equal to the values at eastern coast of Luzon, i.e. at grid $(41,1)$.

During summer the southwest monsoon drives the SCS water northward and transports them to the region east of Taiwan. However, the associated volume transports are not directly observed. Wyriki (1961) estimated that $3 \mathrm{~Sv}$ water 
Model basin of Luzon Strait Area

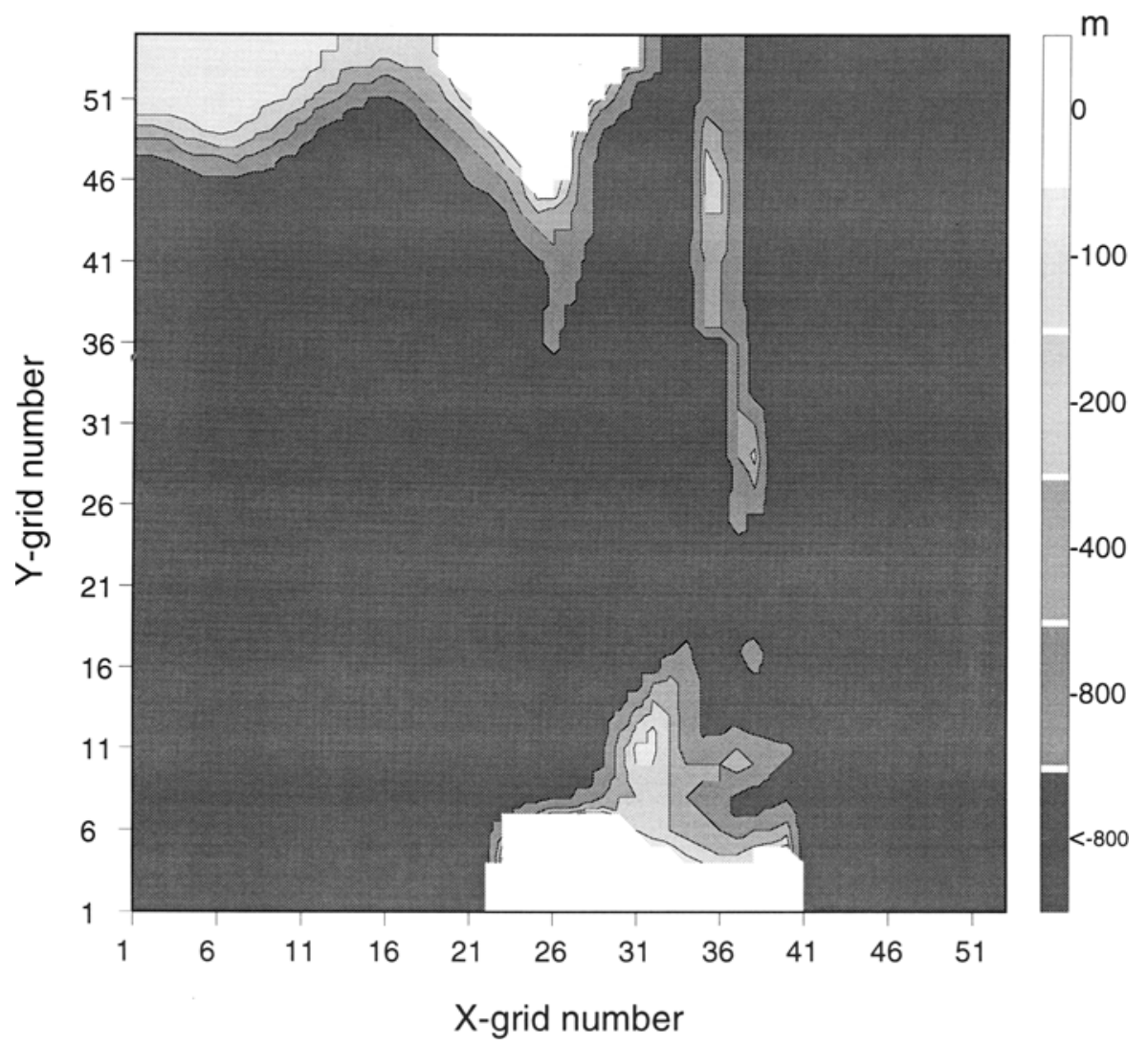

Fig. 6. Topography of the model basin; the annotations are grid numbers in the horizontal axis and the depths are in meters.

from Java Sea enters the SCS at $2^{\circ} \mathrm{N}$ and $2.5 \mathrm{~Sv}$ water flows out the SCS through the LS in summer. Hence, $0.5 \mathrm{~Sv}$ water flows northward into the Taiwan Strait. Shaw and Chao (1994) used these values in their model study of the circulation in the SCS. Based on the observations of Chuang (1986), Jan et al. (1994) estimated that the volume transport entering the Taiwan Strait in summer is around $1 \mathrm{~Sv}$. Therefore, we assume that $2.6 \mathrm{~Sv}$ SCS water flows into the model domain from the southern open boundary to the west of Luzon and $1 \mathrm{~Sv}$ transport is withdrawn from the Taiwan Strait during the spin up period. Hence, a net $1.6 \mathrm{~Sv}$ SCS water passes the LS and joins the Kuroshio at east of Taiwan.

Two experiments are presented in the following for both Cases I and II. In the first experiment, Case I- 1 and Case II-1, the SCS water has the same (T, S) values as those of Kuroshio at grid $(41,1)$. In the second experiment, Case I2 and Case II-2, the temperature of the SCS water below 500 $m$ is assumed to be the same as that of the Kuroshio water at grid $(41,1)$ and becomes cooler in the $50-400 \mathrm{~m}$ depth range. The maximum temperature difference between Kuroshio and the SCS water is $3^{\circ} \mathrm{C}$ at $125 \mathrm{~m}$. Figure 8 displays the temperature profiles of the SCS water of these experiments. The salinity of the SCS water in the second experiment is calculated from its temperature according to the T-S curve of SCS water in Fig. 2(b). The horizontal eddy viscosity in momentum equations and eddy diffusivity in temperature and salinity equations are $2 \cdot 10^{7} \mathrm{~cm}^{2} / \mathrm{s}, 2 \cdot 10^{6}$ $\mathrm{cm}^{2} / \mathrm{s}$, respectively, in all cases. The vertical eddy viscosity and diffusivity are both $2 \mathrm{~cm}^{2} / \mathrm{s}$.

The boundary conditions are the no normal gradient for all the temperatures, salinities and velocity fields at the northern open boundaries. At the southern open boundary west of Luzon, we use the no normal gradient condition for the velocity field and impose the SCS water property if the water flows into the model domain and use the no normal gradient condition for the outflow situation. For the open boundary east of Luzon, the jet is clamped to its initial strength. At the eastern and western walls, the no slip condition is imposed for the velocity field and no normal gradient condition is used for the temperature and salinity fields. The volume transport conditions are that $2.6 \mathrm{~Sv}$ water flows into the model domain west of Luzon and $1 \mathrm{~Sv}$ water flowing out through PHC with a net $1.6 \mathrm{~Sv}$ water flowing out LS to join Kuroshio east of Taiwan in all cases. Hence, the 

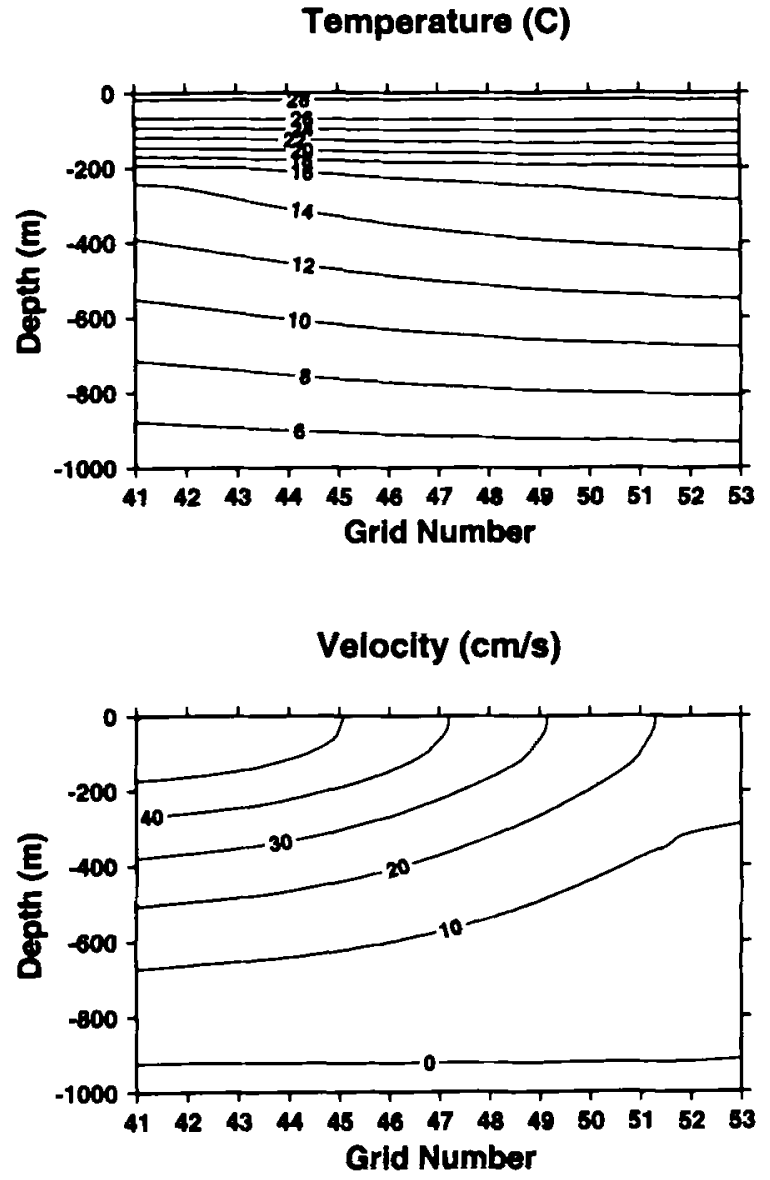

Fig. 7. Zonal temperature and velocity transects of the model Kuroshio for Case I at southern open boundary east of Luzon. transport of Kuroshio is $20 \mathrm{~Sv}$ at the southern boundary east of Luzon and becomes $21.6 \mathrm{~Sv}$ at the northern open boundary east of Taiwan in Case I. The Kuroshio transport increases to $24.3 \mathrm{~Sv}$ and $25.9 \mathrm{~Sv}$ east of Luzon and Taiwan, respectively, in Case II.

The numerical model was integrated for 200 days. No appreciable change occurred in the volume-averaged kinetic energy from 100 to 200 days. Figure 9 depicts the horizontal distribution of the temperature and velocity fields at $125 \mathrm{~m}$ and $325 \mathrm{~m}$ of Case I- 1 at day 200 . In this case, we omit the effect of the difference in the stratification between the waters at two sides of Luzon. According to the distribution at $325 \mathrm{~m}$, a portion of Kuroshio water flows northwestward through the Balintang Channel and forms a large anticyclone loop in the LS. The distribution at $125 \mathrm{~m}$ indicates that the circulation to the west of LS is also in a clockwise orientation. The comparison of the results shown in Figs. 9 and 13, which show the flow under the same initial and boundary conditions as that of Case I-1 on a f-plane, reveals that the planetary $\beta$-effect is a main factor to affect the Kuroshio loop structure in the LS. This effect will be discussed further in the next section. With the occurrence of a large clockwise loop current in the LS, the velocity is northwestward to the north of Luzon and becomes northeastward to the south of Taiwan. Hence, the northward transport west of Luzon has to follow the western boundary of the basin and forms a clockwise circulation. From the result of Case I-1, we find that the westward intrusion of Kuroshio water across LS still occurs even there is a $2.6 \mathrm{~Sv}$ northward transport of SCS water west of Luzon.

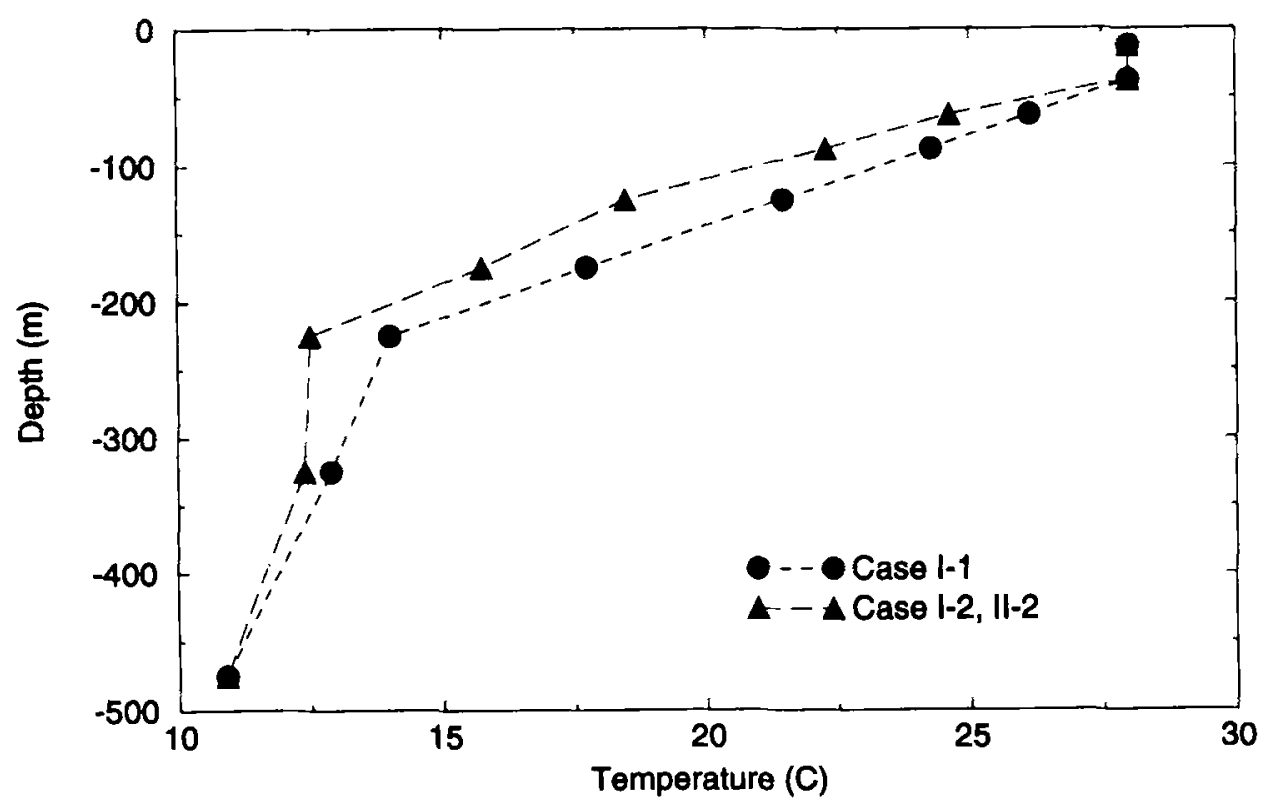

Fig. 8. Vertical temperature profiles of the upper $500 \mathrm{~m}$ of the modelled SCS water. 


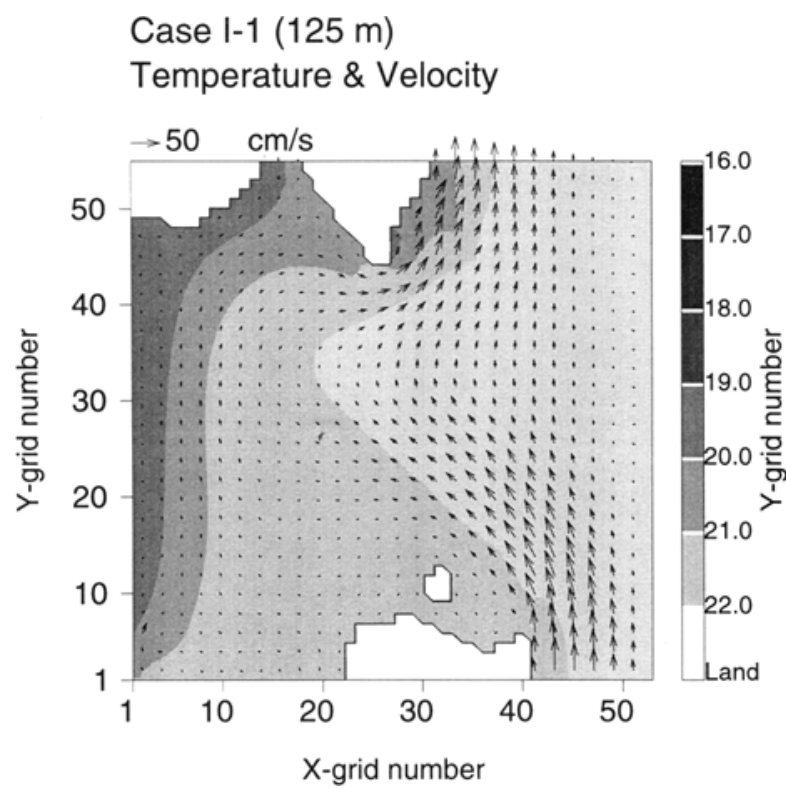

Case l-1 (325 m)

Temperature \& Velocity

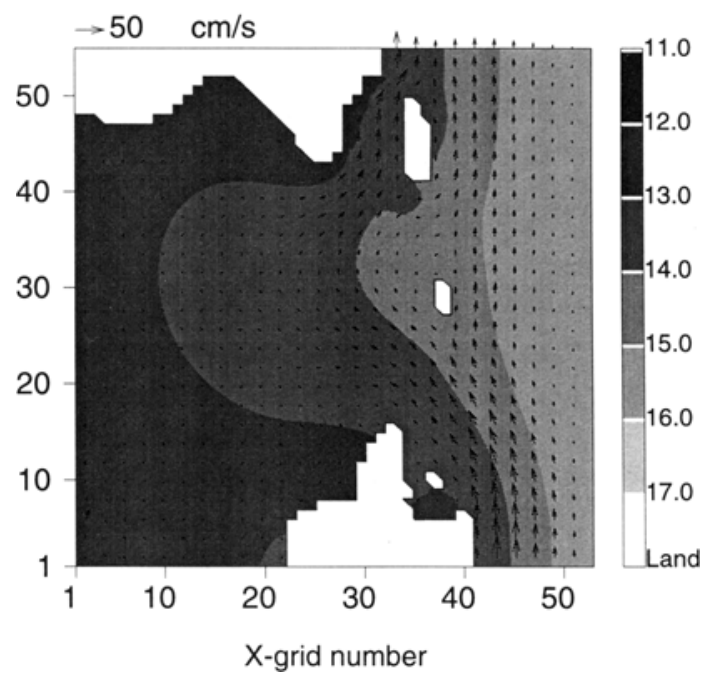

Fig. 9. Horizontal temperature and velocity distributions at $125 \mathrm{~m}$ and $325 \mathrm{~m}$ of Case $\mathrm{I}-1$ at day 200 .
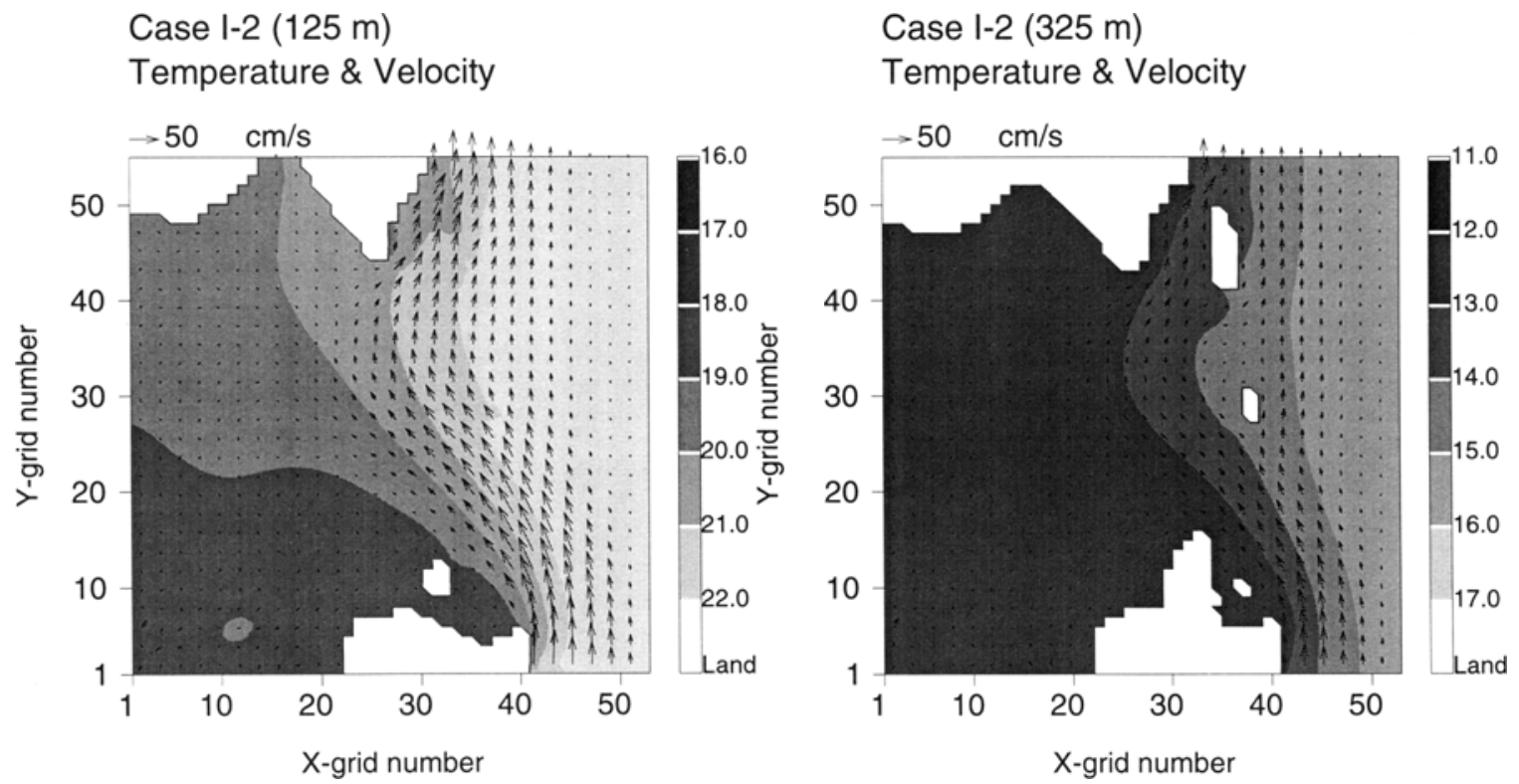

Fig. 10. Horizontal temperature and velocity distributions at $125 \mathrm{~m}$ and $325 \mathrm{~m}$ of Case I-2 at day 200 .

The distribution at $125 \mathrm{~m}$ shown in Fig. 9 also indicates that the temperature along the western boundary is cooler than that of Kuroshio water in the LS, though the water properties of the SCS and Kuroshio waters are the same in this case. The occurrence of cold water along the western boundary may be attributed to the withdrawal of $1 \mathrm{~Sv}$ water from a stratified flow through a shallow water channel, i.e. at PHC, which is $125 \mathrm{~m}$ deep. This kind of selective with- drawal and a clockwise circulation west of LS can induce a surface jet in the upper $125 \mathrm{~m}$ along the western boundary, Fig. 12(a). Due to geostrophy, a northward surface jet must have cooler water at its western side to maintain the vertical shear of the northward velocity component. However, this western wall is artificial, so the abovementioned process may be irrelevant to any observations.

Figure 10 illustrates the horizontal distribution of tem- 
Case II-1 (325 m)

Temperature \& Velocity

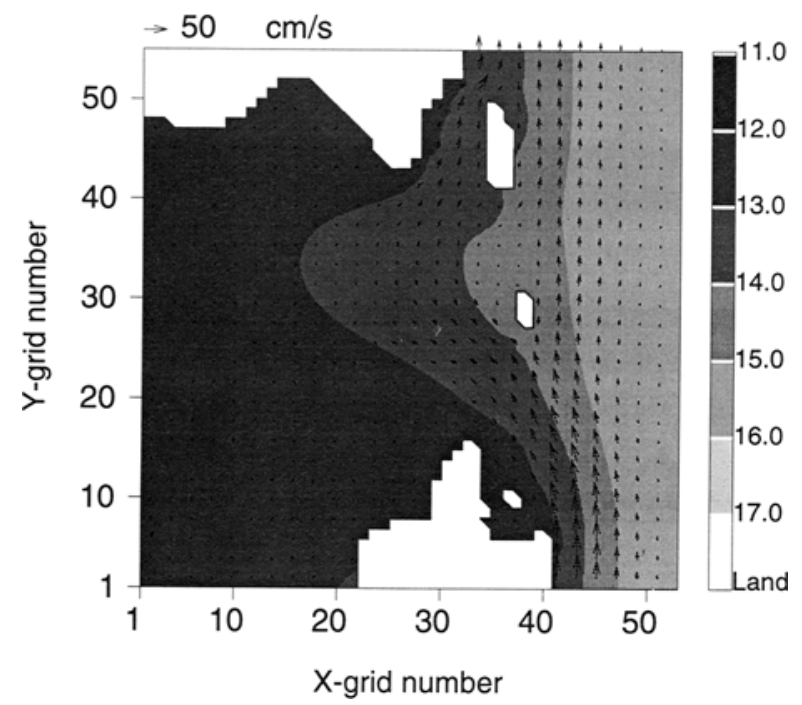

Fig. 11. Horizontal temperature and velocity distributions at 325 m of Case II-1 at day 200.

perature and velocity fields at $125 \mathrm{~m}$ and $325 \mathrm{~m}$ of Case I2 at day 200 . In this case, the SCS water has a stronger thermocline. As the distribution at $325 \mathrm{~m}$ reveals, the separation of Kuroshio in front of the ridge at east of LS still occurs. However, the westward intrusion of Kuroshio water from the Balingtan Channel is weakened and the Kuroshio front only forms a small loop structure in the LS. This pattern resembles that in Fig. 4. Also, the distribution at 125 $m$ of Case I-2 indicates that the flow in the northern part of LS is mainly northward. As this flow hits the southern tip of Taiwan, some water to the west of LS turns toward the northwest and enters into the southwest offshore of Taiwan. Since this portion of water is from the west wing of the northward jet in LS, its vertical component of relative vorticity should be positive. Hence, there is a continuous flux of positive relative vorticity into the southwest offshore of Taiwan to the south of Taiwan. Then we can expect the formation of a counterclockwise circulation in that area. Therefore, the clockwise circulation west of LS and the surface jet along the western boundary of Case I-1 can no longer exist in Case I-2, and the cold SCS water from west of Luzon is confined to the south of grid $y=30$.

The numerical results of Cases II- 1 and II- 2 yield a flow pattern very similar to that of Case I-1 and I-2 (Figs. 9 and 10), except that the extent of westward intrusion of Kuroshio water across the LS is significantly reduced in Case II-1. Figure 11 displays the horizontal distribution of temperature and velocity at $325 \mathrm{~m}$ of Case II-1 at day 200 . From this figure, we can infer that an increase in Kuroshio transport to the east of Luzon can also reduce the strength of its loop (a)

Case II-1 Velocity $(\mathrm{cm} / \mathrm{s})$

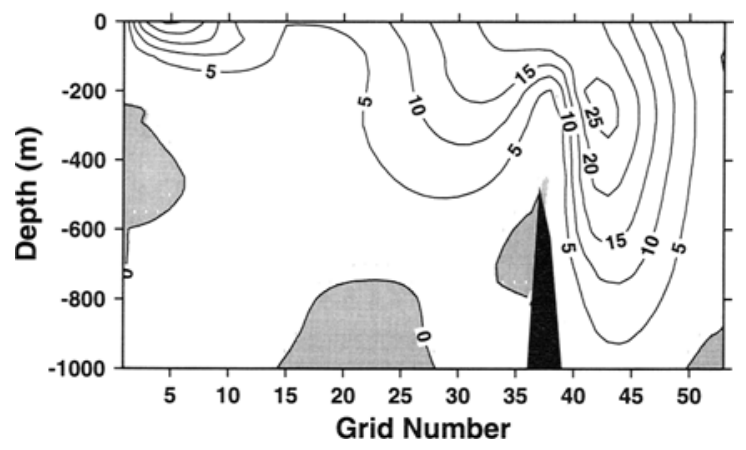

(b)

Case II-2 Velocity $(\mathrm{cm} / \mathrm{s})$

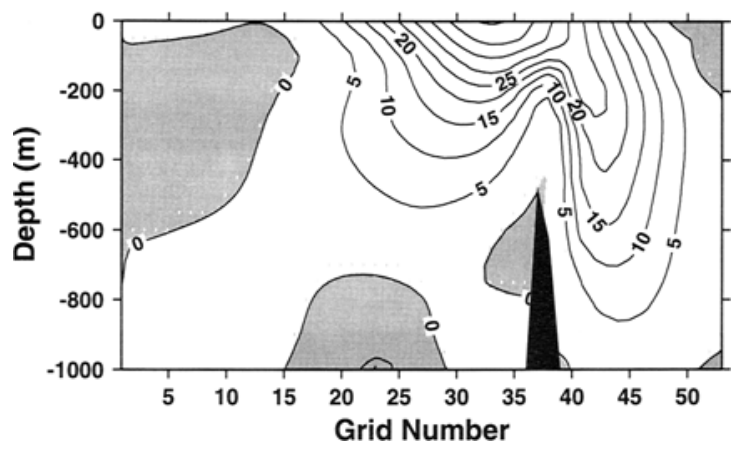

Fig. 12. Zonal section of northward velocity at grid $y=32$ of Case II-1 (a) and Case II-2 (b). The dark area is a submarine ridge and the light shaded area is the region of the southward flow.

current structure in the LS. The dynamics of this effect will be discussed in the next section.

Figure 12 presents a zonal velocity section at grid $y=$ 32 of the Case II- 1 and Case II-2. This figure reveals the obvious separation of Kuroshio into two cores by the ridge east of LS. The core east of the ridge has a similar structure in both cases and the core to the west of the ridge has a stronger surface velocity in Case II-2. This finding is attributed to the convergence of Kuroshio and the cooler SCS water in the LS. As Fig. 12 reveals, a surface jet occurs near the western wall in Case II-1; this jet is absent in Case II-2. The velocity near the western wall becomes southward from surface to $600 \mathrm{~m}$ deep in Case II-2. Hence, the circulation southwest of Taiwan changes from a clockwise orientation in Case II-1 to the counterclockwise sense in Case II-2. The counterclockwise circulation in the northern SCS west of LS and the presence of a meridional front in the LS comprise the typical flow pattern during summer (Wang and Chern, 1996).

We can conclude from above numerical results that the northward flowing Kuroshio to the east of Luzon separates into two branches as it encounters a ridge system east of LS. 
The branch to the east of the ridge continues to flow north and the other branch enters the LS through the Balintang Channel. The portion of Kuroshio water in the LS always forms an anticyclone loop current there. The present results confirm that two factors can influence the strength of this loop current: the transport of Kuroshio to the east of Luzon and the difference between the vertical stratification of Kuroshio and SCS waters. A stronger thermocline in the SCS water and/or a larger Kuroshio transport can inhibit the development of the loop current in the LS.

\section{Discussion and Concluding Remarks}

The LS, a wide channel between Taiwan and Luzon islands, has a latitude ranging from $18^{\circ} \mathrm{N}$ to $22^{\circ} \mathrm{N}$. The fact that the change of Coriolis parameter across the strait to a mean value of around 0.19 implies that the planetary $\beta$-effect has a strong influence on the flow in this area. As the jet east of Luzon flows northward, it must induce a negative relative vorticity. Hence, an anticyclone loop is always generated in the LS (Li et al., 1996).

The hydrographic data in the previous section reveal that as the Kuroshio passes Luzon island, a portion of it flows through the Balintang Channel and enters the Luzon Strait. A nearly meridional front between Kuroshio and SCS waters is formed there. According to the numerical model simulation in Fig. 12, the flow west of this front and at a depth below $600 \mathrm{~m}$ is quite weak. Therefore, a reduced gravity two-layer model, in which the lower layer is at rest, can be used to discuss the dynamic processes that influence the frontal structure in the LS. Consequently, the equations that govern the front in the LS are as follows:

$$
\begin{aligned}
& \frac{\partial u}{\partial t}+u \frac{\partial u}{\partial x}+v \frac{\partial u}{\partial y}-\left(f_{\circ}+\beta_{\mathrm{o}} y\right) v=-g^{\prime} \frac{\partial h}{\partial x}, \\
& \frac{\partial v}{\partial t}+u \frac{\partial v}{\partial x}+v \frac{\partial v}{\partial y}-\left(f_{\circ}+\beta_{\circ} y\right) u=-g^{\prime} \frac{\partial h}{\partial y}, \\
& \frac{\partial h}{\partial t}+\frac{\partial(h u)}{\partial x}+\frac{\partial(h v)}{\partial y}=0,
\end{aligned}
$$

where $x$ and $y$ denote the eastward and northward coordinates, respectively, $u$ and $v$ represent the upper layer horizontal velocity components along those directions, $f_{\mathrm{o}}+\beta_{\mathrm{o}} y$ the local Coriolis parameter, $g^{\prime}$ is reduced gravity, and $h$ denotes the upper-layer depth. A line along which $h(x, y$, $t)=0$ marks the western boundary of the front.

For a meridional front, its horizontal length scales may differ in the $x$ and $y$ directions. Herein, we use $l$ and $L$ to characterize the frontal width and the length scale along the front, and use $T$ to represent a typical time scale for the frontal motion. We also assume a upper layer thickness variation scale $H$; the geostrophic velocity along the front is then of the order $V=g^{\prime} H / f_{0} l$. From the continuity equation, a cross-front velocity scale $U=V l / L$ can be obtained. With these scales, the dimensionless equations of motion are as follows:

$$
(s \omega) \frac{\partial u}{\partial t}+\left(\varepsilon s^{2}\right)\left(u \frac{\partial u}{\partial x}+v \frac{\partial u}{\partial y}\right)-(1+\beta y) v=-\frac{\partial h}{\partial x},
$$

$\left(\frac{\omega}{s}\right) \frac{\partial v}{\partial t}+\varepsilon\left(u \frac{\partial v}{\partial x}+v \frac{\partial v}{\partial y}\right)+(1+\beta y) u=-\frac{\partial h}{\partial y}$,

$\omega \frac{\partial h}{\partial t}+(\varepsilon s) \frac{\partial(h u)}{\partial x}+(\varepsilon s) \frac{\partial(h v)}{\partial y}=0$

where $\varepsilon=\left(g^{\prime} H\right) /\left(f_{0} l\right)^{2}, \beta=\beta_{0} L / f_{0}, s=l / L$ and $\omega=1 / f_{0} T$.

Following the approach of Cushman-Roisin (1986), $u$ and $v$ can be expanded by the f-plane geostrophic velocities, when $\varepsilon, \beta$ and $\omega$ are sufficiently small and $s \leq 1$, as

$$
\begin{aligned}
& u=-\frac{\partial h}{\partial y}-\varepsilon J\left[h, \frac{\partial h}{\partial x}\right]+\beta y \frac{\partial h}{\partial y} \\
& v=\frac{\partial h}{\partial x}-\varepsilon s^{2} J\left[h, \frac{\partial h}{\partial y}\right]-\beta y \frac{\partial h}{\partial x}
\end{aligned}
$$

where higher order terms of $O\left(\varepsilon^{2}, \beta^{2}, \varepsilon \beta\right)$ are neglected and $J[a, b]=a_{x} b_{y}-a_{y} b_{x}$ denotes the Jacobian operator.

Then, a single equation governing the evolution of the upper layer thickness $h$ can be deduced as

$$
\begin{aligned}
\frac{\partial h}{\partial t}= & \frac{\beta \varepsilon s}{\omega} h \frac{\partial h}{\partial x}+\frac{\varepsilon^{2} s}{\omega} J \\
& {\left[h, h \frac{\partial^{2} h}{\partial x^{2}}+s^{2} h \frac{\partial^{2} h}{\partial y^{2}}+\frac{1}{2}\left(\left(\frac{\partial h}{\partial x}\right)^{2}+s^{2}\left(\frac{\partial h}{\partial y}\right)^{2}\right)\right] . }
\end{aligned}
$$

When $s=1$ the above equation becomes the frontal geostrophic equation of Cushman-Roisin (1986). The magnitude of $\varepsilon$ and $\beta$ denotes the relative importance of the inertial term, which is related to the frontal strength, and the planetary $\beta$-effect on the frontal structure. For the Kuroshio front in the LS (Fig. 4), we can infer that the front width is less than $100 \mathrm{~km}$ and its meridional length scale exceeds 200 $\mathrm{km}$. For the numerical simulations performed here, the computed velocity values in the LS are used to estimate $\varepsilon$. The maximum northward surface velocity in the LS is about 20 $\mathrm{cm} / \mathrm{s}$ in Case II-1 and $50 \mathrm{~cm} / \mathrm{s}$ in Case II-2, Fig. 12. The 
corresponding values for the Cases I- 1 and I- 2 are nearly 15 $\mathrm{cm} / \mathrm{s}$ and $35 \mathrm{~cm} / \mathrm{s}$, respectively, indicating that both the increase of Kuroshio transport east of Luzon and a stronger vertical stratification in the SCS water enhance the northward velocity in the LS. With $f_{\mathrm{o}}=5 \cdot 10^{-5} \mathrm{~s}^{-1}, l=100 \mathrm{~km}, \varepsilon$ equals $0.03,0.04,0.07$ and 0.1 for Cases I-1, II-1, I-2 and II-2, respectively; and $\beta$ equals 0.08 for $L=200 \mathrm{~km}$.

The temperature jump across the Kuroshio front in the LS is around $4^{\circ} \mathrm{C}$ (Fig. 4); this gives $g^{\prime}$ about $0.4 \mathrm{~cm} / \mathrm{s}^{2}$. The fact that the temperature difference between Kuroshio and SCS waters occurs primarily in the upper $500 \mathrm{~m}$ (Fig. 2), allows us to assume that the scale of the upper layer thickness $H$ is $500 \mathrm{~m}$. We then have a velocity scale $V=40 \mathrm{~cm} /$ $s$ and $\varepsilon=0.08$. This estimation is rather general, in which a double value of $H$ may yield $V=80 \mathrm{~cm} / \mathrm{s}$ and $\varepsilon=0.16$. Nevertheless, these values indicate that the inertial effect is of the same order as the planetary $\beta$ effect for the summertime front in the LS.

When the strength of the front is sufficiently weak, i.e. $\varepsilon<\beta$, then Eq. (9) reduces to

$$
\frac{\partial h}{\partial t}=h \frac{\partial h}{\partial x}
$$

if $\omega=\beta \varepsilon s$. This simplified equation implies that the planetary $\beta$-effect continuously pushes the front position westward. The contour of the upper layer thickness, $h$, tends to be in the zonal direction, i.e. $(\partial h) /(\partial x)=0$. The large loop in the LS of Case I-1 (Fig. 9) is attributed to this effect. Hence, the northward transport of water west of Luzon alone cannot prevent the westward turning of Kuroshio in the LS if we neglect the difference in the vertical stratification between Kuroshio and the SCS waters.

In contrast, when $\beta<<\varepsilon$, the term involving $\beta$ in Eq. (9) is negligible. Meanwhile, for a long meridional front, its aspect ratio $s$ is small, i.e. around 0.5 for the front in the LS. Hence, we can neglect the terms involving $s^{3}$ in Eq. (9) and obtain

$$
\frac{\partial h}{\partial t}=\frac{\varepsilon^{2} s}{\omega} J\left[h, h \frac{\partial^{2} h}{\partial x^{2}}+\frac{1}{2}\left(\frac{\partial h}{\partial x}\right)^{2}\right] .
$$

For any given $h(x, y, t)$, if $(\partial h) /(\partial y)=0$, the right hand side of Eq. (10) is always zero. Hence $h(x)$ becomes a solution, implying that a steady meridional front is possible. Herein, we ran a numerical model, Case 1-3, with the same initial and boundary conditions of Case I- 1 on a f-plane. Figure 13 presents its horizontal distribution of temperature and velocity fields at $325 \mathrm{~m}$. Without the $\beta$-effect, the isotherms east of Luzon are primarily in the meridional direction and the large loop west of LS in Fig. 9 is absent. The above findings are consistent with the above analysis. In addition, the small

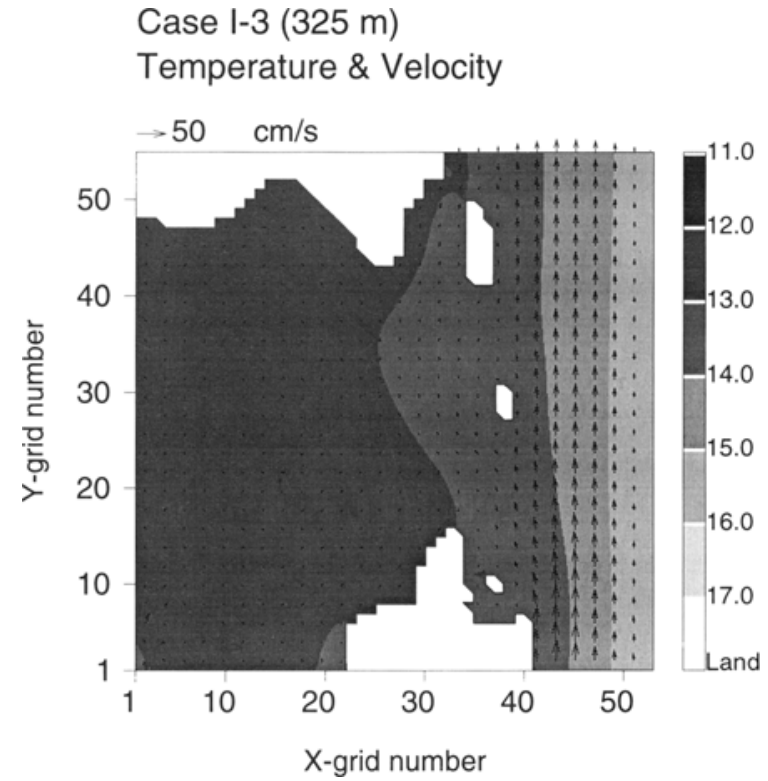

Fig. 13. Horizontal temperature and velocity distributions at 325 m of Case I-3 at day 200.

loop structure in Fig. 13 is attributed to the passing of a stratified flow over a long ridge aligned with the free-stream direction on a f-plane (Fig. 9 of Merkine and Kalnay-Rivas, 1976).

Consider a situation in which $\beta$ and $\varepsilon$ are of the same order of magnitude, which corresponds to Cases I-2, II-2 and the summertime front in the LS, Eq. (9) indicates that a stationary loop front is possible due to the balance between planetary $\beta$ and inertial effects. This kind of structure dynamically resembles the intermediate scale vortex discussed by Matsuura and Yamagata (1982). The primary difference between the loop front and large vortex is that a long meridional front may have a small aspect ratio $s$. Consequently, the cross-front momentum equation, Eq. (4), reduces to a geostrophic balance. Notably, the balance between weak nonlinearity and $\beta$-effect occurs only in the along frontal direction, Eq. (5).

From the above discussion we can infer that $\beta$ and $\varepsilon$ are two main parameters that influence the shape of the Kuroshio front in the LS. As the southwest winds drive the strongly stratified SCS water northward, the convergence of the SCS water and Kuroshio water in the LS enhance the strength of their front. Hence the $\varepsilon$ increases and prevents the development of a loop current in the LS. During winter, Farris and Wimbush (1996) noted that the Ekman transport of the northeast winds can push the Kuroshio surface water westward and induce a loop current in the LS. They also indicated that this kind of motion occurs roughly fifty days after the onset of the northeast monsoon. This time lag may 
be attributed to the fact that the strongly stratified SCS water still exists west of LS after the onset of the northeast winds. However, the northeast monsoon gradually pushes the SCS water southward (Shaw and Chao, 1994), and decreases the Kuroshio's transport to the east of Taiwan (Wyriki, 1961). When the strongly stratified SCS water is absent in the northern SCS west of LS, our model results indicate that a large loop current in the LS is possible even without the surface winds. Consequently, the Ekman transport associated with the northeast winds enhances its development.

The numerical results also demonstrate that the ridge east of LS can separate the Kuroshio into two branches. The branch to the west of the ridge can also pass through the LS and converge with the SCS water in the LS. From the CTD casts east of Taiwan during summer, we can infer that Kuroshio also has two cores in its velocity distribution. The SCS water from the LS contributes mainly to the nearshore core and, consequently, is the source of the observed strong thermocline in Kuroshio during summer east of Taiwan (Chern and Wang, 1994).

\section{Acknowledgements}

The authors would like to thank the National Science Council of the Republic of China for financially supporting this work under Contract No. NSC 85-2611-M-002a-015OS.

\section{References}

Chao, S. Y., P. T. Shaw and S. Y. Wu (1996): Deep water ventilation in the South China Sea. Deep Sea Res., I, 43, 445466.

Chern, C. S. and J. Wang (1994): Influence of the seasonal thermocline on the intrusion of Kuroshio across the continental shelf northeast of Taiwan. J. Oceanogr., 50, 691-711.

Chern, C. S. and J. Wang (1995): The seasonal variations of Kuroshio's axis at east of Taiwan. 8th PAMS \& JECSS Workshop, 26-28 September, Ehime University, Matsuyama, Japan.

Chu, T. Y. (1976): Study of the Kuroshio current between Taiwan and Ishigakijima. Acta Oceanogr. Taiwanica, 6, 1-24.

Chuang, W. S. (1986): A note on the driving mechanisms of current in the Taiwan Strait. J. Oceanogr. Soc. Japan, 42, 355-
361.

Cushman-Roisin, B. (1986): Frontal geostrophic dynamics. J. Phys. Oceanogr., 16, 132-143.

Farris, A. and M. Wimbush (1996): Wind-induced Kuroshio intrusion into the South China Sea. J. Oceanogr., 52, 771-784.

Jan, S., C. S. Chern and J. Wang (1994): A numerical study on currents in the Taiwan Strait during summertime. La mer, 32, 225-234.

Li, W., Q. Liu and S. P. Cheng (1996): The effect of break in western boundary on the western boundary current. Acta Oceanogr. Taiwanica, 35(2), 141-153.

Liu, C. T., Y. Yang, S. P. Cheng, C. S. Wang and Q. Liu (1995): The counter current southeast of Lanyu Island. Acta Oceanogr. Taiwanica, 34(1), 41-56.

Matsuura, T. and T. Yamagata (1982): On the evolution of nonlinear planetary eddies larger than the radius of deformation. J. Phys. Oceanogr., 12, 440-456.

Merkine, L. and E. Kalnay-Rivas (1976): Rotating stratified flow over finite isolated topography. J. Atmos. Sci., 33, 908-922.

Nitani, H. (1972): Beginning of the Kuroshio. p. 129-163. In Kuroshio, University of Washington Press, Seattle, WA.

Semtner, A. J. (1974): An oceanic general circulation model with bottom topography. Numerical Simulation of Weather and Climate, Tech. Rep. 9, Dept. of Meterology, UCLA, 99 pp.

Semtner, A. J. (1986): Finite difference formulation of a world ocean model. In Proceedings of the NATO Advanced Study Institute on Advanced Physical Oceanographic Numerical Modelling, ed. by J. J. O’Brien, D. Reidel Publishing Co., Dordrecht, 608 pp.

Shaw, P. T. and S. Y. Chao (1994): Surface circulation in the South China Sea. Deep Sea Res., I, 41, 1663-1683.

Shaw, P. T., S. Y. Chao, K. K. Liu, S. C. Pai and C. T. Liu (1996): Winter upwelling off Luzon in the northern South China Sea. J. Geophys. Res., 101, C7, 16435-16448.

Wang, J. and C. S. Chern (1987): The warm-core eddy in the northern South China Sea, I. Preliminary observations on the warm-core eddy. Acta Oceanogr. Taiwanica, 18, 92-103.

Wang, J. and C. S. Chern (1996): Some aspects on the circulation in the northern South China Sea. La mer, 34(3), 246-257.

Wyriki, K. (1961): Physical oceanography of the Southeast Asian waters. NAGA Report, 2, Scientific Results of Marine Investigations of the South China Sea and the Gulf of Thailand, Scripps Institution of Oceanography, La Jolla, California, 195 pp. 